\title{
Mixed-Methods Study on Caregiver Strain, Quality of Life, and Perceived Health
}

\author{
Claudio Di Lorito ${ }^{\mathrm{a}, *}$, Alessandro Bosco ${ }^{\mathrm{b}}$, Maureen Godfrey ${ }^{\mathrm{a}}$, Marianne Dunlop ${ }^{\mathrm{a}}$, Juliette Lock $^{\mathrm{a}}$, \\ Kristian Pollock ${ }^{\mathrm{c}}$, Rowan H. Harwood ${ }^{\mathrm{c}}$ and Veronika van der Wardt ${ }^{\mathrm{d}}$ \\ ${ }^{a}$ Division of Rehabilitation, Ageing and Wellbeing, School of Medicine, University of Nottingham, Nottingham, \\ United Kingdom \\ ${ }^{\mathrm{b}}$ Division of Psychiatry and Applied Psychology, School of Medicine, University of Nottingham, Nottingham, \\ United Kingdom \\ ${ }^{\mathrm{c} S c h o o l}$ of Health Sciences, University of Nottingham, Nottingham, United Kingdom \\ ${ }^{\mathrm{d}}$ Zentrum für Methodenwissenschaften und Gesundheitsforschung, Abteilung für Allgemeinmedizin, Präventive \\ und Rehabilitative Medizin, Philipps-Universität Marburg, Marburg, Germany
}

Handling Associate Editor: Lori Newkirk

Accepted 6 January 2021

Pre-press 12 February 2021

\begin{abstract}
.
Background: Caring for someone with dementia is associated with negative and positive experiences. There is little evidence based on large datasets.

Objective: To present data around the experience of caring for someone with dementia, to identify support (emotional and practical) needs, and inform future service provision.

Methods: A mixed-methods study embedded in the Promoting Activity, Independence and Stability in Early Dementia (PrAISED) Randomized Controlled Trial. We administered questionnaires on strain, quality of life (QoL), and perceived health to 301 caregivers and assessment of cognitive performance, depression, anxiety, and disability in activities of daily living to 301 participants with dementia. Data were analyzed through descriptive and modelling statistics. A subsample of 20 patient-caregiver dyads were qualitatively interviewed. Data around caregivers' experience of providing care were extrapolated and analyzed through inductive thematic analysis.

Results: There were significant negative associations between caregiver strain and QoL $(p<0.01)$ and between caregiver age and QoL $(p<0.01)$, and significant positive associations between caregiver strain and disability $(p<0.01)$, cognitive impairment $(p<0.01)$, depression $(p<0.05)$, and anxiety of the person with dementia $(p<0.05)$. Older caregivers reported a lack of support, reinforced by their reluctance to seek help. All caregivers reported contradictory emotions associated with caring and accumulation of strain over time.

Conclusion: While there is recognition that it is essential to support caregivers, dedicated intervention programs, and support strategies to respond to the needs of older caregivers are still needed.
\end{abstract}

Keywords: Caregiver, caregiver exhaustion, dementia, quality of life, randomized controlled trial

\footnotetext{
${ }^{*}$ Correspondence to: Dr. Claudio Di Lorito, Room B109, Queen's Medical Centre, Nottingham NG7 2TU, United Kingdom. Tel.: +447453717277; E-mail: claudio.dilorito@nottingham. ac.uk.
}

\section{INTRODUCTION}

There are currently 700,000 families in the United Kingdom involved in the care of someone with dementia. Almost half of these families provide care 24 hours a day, seven days a week $[1,2]$. In $66 \%$ of the 
cases, the caring role lasts more than one year and in $33 \%$ more than five years [3].

The term caregiver strain or burden denotes the negative impact of caring for someone with dementia on physical, mental, emotional, and social wellbeing [4]. Caring duties can heavily impact on the mental health of caregivers [5]. Several studies have linked caregiver's burden to negative effects on psychological health [6-8], including depression [9, 10], anxiety [7, 11-13], and psychiatric morbidity [14]. Caregiver burden has also been linked to physical illhealth, such as heart conditions, compromised immune system, and with higher risk of early mortality [3, 15-24]. Because of their caring duties, caregivers may also experience reduced social opportunities [25] and be at risk of social isolation [26], as well as reduced quality of life (QOL) [27].

The extent of effects on caregiver's health seems to be time-dependent (i.e., linked to the length of care that the caregiver provides). There are currently two opposing theories explaining the relationship between length of care and effects on caregiver's health. The so-called "Adaptation hypothesis" posits that the longer the care, the more the carer adapts to manage burden $[28,29]$. The "wear and tear" hypothesis, instead, theorizes that longer periods of care are linked to increased carer burden [30, 31].

Although the scientific literature has traditionally focused on negative outcomes [32], caregivers can also experience positive reactions in caregiving situations [33-35]. Sources of satisfaction include experiencing a sense of togetherness, feelings of belongingness, personal reward and growth [36], altruism and reciprocity [37], protection from negative self-perceptions, repaying the cared-for for past services, honoring vows, and religious principles [38].

To date, there is little mixed-methods research around the experience of caring for someone with dementia based on large datasets [39]. This study aimed to present quantitative and qualitative data around the experience of caring for someone with dementia, to identify support (emotional and practical) needs and inform future service provision. The objectives were to:

- Determine the degree of caregivers' strain, QoL and perceived health;

- Test the association of caregivers' strain, QoL and perceived health with sociodemographic characteristics of caregivers and clinical outcomes of the person with dementia;
- Report on the caregivers' individual experience of caring for the person with dementia.

\section{MATERIALS AND METHODS}

\section{Study design}

This was a mixed-methods cross-sectional study comprising a quantitative and a qualitative element. It was based on data collected in the Promoting Activity, Independence and Stability in Early Dementia (PrAISED) Randomized Controlled Trial, which tests the clinical and cost-effectiveness of a therapy intervention to promote activity and independence in people with early dementia or mild cognitive impairment [40]. The PrAISED therapy intervention lasts 12 months and consists of individually-tailored physical, dual-task exercises, and functional activities of daily living delivered in participants' homes by multidisciplinary teams of physiotherapists (PTs), occupational therapists (OTs), and rehabilitation support workers (RSWs).

\section{Participants}

Three-hundred and one dyads of participants with dementia and their caregivers $(n=602)$ were included in the quantitative element of this study. Inclusion criteria for the participant with dementia were: aged 65 years or over; having a diagnosis of mild cognitive impairment or dementia; scoring 13-25 (out of 30) in the Montreal Cognitive Assessment (MoCA) [41]; being able to walk without human help, communicate in English, see and hear, perform neuropsychological tests, and give consent to participate. Inclusion criteria for the caregiver were: being a family member, informal caregiver, or friend who knew the participant with dementia well (defined as having contact with them for at least one hour per week via internet, telephone, or in person); being willing and able to act as an informant and to be a research participant.

For the qualitative element of this study, the main researcher (CDL) accessed the PrAISED RCT database and purposively selected 20 participants with dementia receiving the PrAISED intervention at the time of recruitment and their respective 20 caregivers $(n=40)$ to be interviewed together (i.e., as a pair). Purposive sampling ensured that the selected participants were as representative as possible of the caregivers and participants with dementia involved in the PrAISED RCT in relation to residence status (i.e., living independently or together) and relationship of 
the caregiver with the participant with dementia (e.g., spouse, child, or sibling).

The PrAISED RCT and process evaluation have received ethical approval by the Bradford Leeds Research Ethics Committee (Reference 18YH/0059). The ISRCTN Registration Number for PrAISED is 15320670 .

\section{Procedures}

At baseline (i.e., month 0 of their involvement in the PrAISED RCT), for the quantitative element of this study, caregivers completed the following questionnaires:

- A socio-demographic questionnaire on age, gender, health, education, relationship to the participant with dementia, employment, residence status, and information related to caring;

- Caregiver strain index (CSI) [42], whose score range is $0-13$, where 13 indicates highest CSI;

- Caregiver health related QoL (EQ5D-5L) [43], a standardized instrument investigating qualityof-life-related outcomes including mobility, selfcare, main activity, social relationship, pain and mood. EQ5D-5L score range is $0-1$, where 1 indicates highest caregiver QoL. The instrument was also used to investigate caregivers' perceived health through the item "your health today", whose score range is $0-100$, where 100 indicates highest perceived health;

The participant with dementia completed the following questionnaires:

- A demographic questionnaire on gender, age, and ethnicity;

- The Montreal Cognitive Assessment (MoCA) [41]. Scores on the MoCA range from zero to 30, with a score of at least 26 generally considered normal.

- The Disability Assessment for Dementia (DAD) [44], whose score range is $0-100$, where 100 indicates lowest disability.

- The Hospital Anxiety and Depression Scale (HADS) [45], a 14-item scale with seven items each for anxiety and depression subscales. Score range for each item is $0-3$. A subscale score over 8 indicates anxiety or depression.

The qualitative element of this study aimed to add an individual dimension to the quantitative assessments by gathering in-depth narratives about the experience of caring for someone with dementia. The selected participants took part in a semi-structured interview in their home at month 3 of their involvement in the PrAISED RCT. An interview topic guide (Supplementary Material) was developed through a collaboration of the research team with two Patient and Public Involvement (PPI) members (MG and $\mathrm{MD}$ ) who had lived experience of caring for someone with dementia. While the topic guide mostly focused on the caregivers' experience of supporting the participant with dementia in the PrAISED RCT, a flexible approach was used in the interview to also explore and capture the experience of caring for the person with dementia more generally (i.e., out of the context of PrAISED). The qualitative interviews were digitally audio-recorded.

\section{Data analysis}

The quantitative data were fully anonymized and transferred in SPSS ${ }^{\circledR} 27.0$ [46]. Pearson's correlation (for normally distributed continuous data), Spearman's correlation (for non-normally distributed data), $t$-test and Mann-Whitney $\mathrm{U}$ test were performed to compare the CSI and EQ5D-5L mean scores based on different caregivers' characteristics. Correlation was computed to test the relationship between CSI, and EQ5D-5L total scores, as well as between CSI and DAD, MoCA, and HADS scores. After checking for assumptions of normality, multi-collinearity, homoscedasticity, linearity and residual statistics, a hierarchical regression analysis was performed to estimate the effect of caregivers' age and gender and participants' MoCA, DAD, and HADS on CSI scores. A level of significance of $p<0.05$ (two-sided) was used.

The qualitative interviews were transcribed by a professional agency. Basic demographic data about participants and MoCA scores for the participants with dementia were extrapolated from the PrAISED database. The full interview transcripts were transferred to $\mathrm{NVivo}^{\circledR} 12.1$ [47]. Interview quotes from the caregivers relating to the experience of caring for the participant with dementia were extrapolated from the transcripts, fully anonymized by the research team, by assigning each participant a unique code (e.g., $\mathrm{C} 01, \mathrm{C} 02$ ), and analyzed through inductive thematic analysis [48].

Two authors (MG and JL) familiarized themselves with the transcripts and identified preliminary 'emerging themes' independently of each other. These were reviewed by two different analysts (CDL and $\mathrm{VvdW}$ ), who synthesized them (i.e., merging 
themes by commonalities) independently of each other into "solidifying themes". Discussions were held among these four analysists about how the themes would best reflect the data set. A codebook, featuring the "final themes" and their operational definitions was developed by CDL and fed back to the other three analysts (MG, JL, and VvdW) for consensus. CDL then recoded all transcripts based on the coding framework.

\section{RESULTS}

\section{Quantitative data}

Of the 301 caregivers included in the quantitative assessments, 198 (66\%) were spouses or partners of the person with dementia. The majority of caregivers were female $(n=214 ; 71.1 \%)$. Their mean age was 69 years $(\mathrm{SD}=13$; range $=21-95)$. The mean age of participants with dementia $(n=301)$ was 80 years $(\mathrm{SD}=7$; range $=65-95)$. The majority were white $(n=294 ; 97.7 \%)$ and male $(n=172 ; 57.1 \%)$. Descriptive statistics of demographic information and outcome measures for caregivers and participants with dementia are presented in Table 1.

The mean CSI score was $4.69(\mathrm{SD}=3.32)$. Female caregivers recorded a mean CSI score of $4.97(\mathrm{SD}=$ $3.26)$ and male caregivers of $4(\mathrm{SD}=3.38)$. The difference was statistically significant, $t(153)=-2.3$, $p<0.05$. Caregivers with pre-existing health conditions had significantly higher mean CSI scores than those without pre-existing health conditions $(U=7856, p<0.01)$. The total mean EQ5D-5L score was 0.84 , out of a possible total of $1.00(\mathrm{SD}=0.19)$. EQ-5D population norm mean for age range 65-74 in England is 0.78 [49]. We found statistically significantly lower mean EQ5D-5L for spouses compared to non-spouses $(U=4798, p<0.01)$, for caregivers living with the person with dementia compared to those not living with them $(U=5578, p<0.01)$, for retired caregivers compared to those actively working $(U=3899, p<0.01)$, and for those with a long-term health condition compared to healthy ones $(U=3766$, $p<0.01$ ).

A linear regression analysis evidenced that younger age was associated with higher QoL, as measured by the EQ5D-5L $[\mathrm{F}(1,295)=30.5, r=0.35$; $p<0.01]$. The mean score for "your health today" was 81 , out of a possible score of $100(\mathrm{SD}=16)$. We found statistically significant better health in children compared to spouses $(U=5123, p<0.01)$, employed caregivers compared to retired ones $(U=4861$, $p<0.01$ ), in caregivers with no long-term health conditions $(U=3703, p<0.01)$, and in those not living with the person with dementia $(U=6020$, $p<0.01$ ).

We found a significant negative, but weak correlation between caregiver burden and caregivers' QoL $(\mathrm{r}=-0.21, p<0.01, n=292)$. Pearson's correlations between caregiver burden and outcomes of the person with dementia were significant (DAD: $\mathrm{r}=-0.37$, $p<0.01, n=291 ;$ MoCA: $\mathrm{r}=-0.17, p<0.01, n=287$; HADS-anxiety: $\mathrm{r}=0.13, p<0.05, n=294$; HADSdepression: $\mathrm{r}=0.13, p<0.05, n=294)$.

A hierarchical regression analysis controlling for age and sex showed that degree of disability and level of anxiety in the person with dementia was significantly associated with caregiver burden (see Table 2). Assumptions of normality, multi-collinearity, homoscedasticity, linearity, and residual statistics were met.

\section{Qualitative data}

All 20 caregivers and 20 participants with dementia approached for the qualitative element of this study agreed to be interviewed (see Table 3 for sample characteristics). Seventeen caregivers (85\%) were female and 17 (all spouses) (85\%) lived with the participant with dementia. The average MoCA score for the participants with dementia was 20 (Range $=15-26$; $\mathrm{SD}=3$ ). The qualitative interviews lasted $48 \mathrm{~min}$ on average (range $=31-65$ ). Four themes were developed: i) Social aspects of caring; ii) Practical aspects of caring; iii) Emotional aspects of caring; and iv) Physical health and caring (Table 4). Participants' quotes are reported by identifying their ID (e.g., C01, C02), relationship to the person with dementia (i.e., $\mathrm{S}=$ sister, $\mathrm{W}=$ wife, $\mathrm{D}=$ daughter, $\mathrm{H}=$ husband) and age.

\section{Practical aspects of caring}

The practical aspects of caring were found to be tightly linked to the level of cognitive impairment of the participant with dementia (see Table 3). Caregivers of more cognitively-deteriorated participants reported that it was time consuming to provide care, as the person needed constant supervision:

I still go out with him myself because for a start, he wouldn't know which bus to get and he would probably end up god knows where. C02, W, 86 years

The caring duties generated added stress to those caregivers who were still working. Some caregivers 
Table 1

Descriptive statistics

\begin{tabular}{|c|c|c|c|c|c|}
\hline & & & $\mathrm{N}^{*}$ & $\%$ & $\begin{array}{l}\text { Mean; standard } \\
\text { deviation; range }\end{array}$ \\
\hline \multirow[t]{37}{*}{ Caregivers } & \multirow[t]{2}{*}{ Gender } & Male & 87 & 28.9 & \\
\hline & & Female & 214 & 71.1 & \\
\hline & \multicolumn{2}{|l|}{ Age } & 301 & 100 & $69.2 ; 12.9 ; 21-95$ \\
\hline & \multirow{6}{*}{$\begin{array}{l}\text { Relationship to participant } \\
\text { with dementia }\end{array}$} & Spouse & 198 & 65.8 & \\
\hline & & Child & 84 & 27.9 & \\
\hline & & Sibling & 3 & 1.0 & \\
\hline & & Other relative & 6 & 2.0 & \\
\hline & & Friend & 6 & 2.0 & \\
\hline & & Other & 4 & 0.7 & \\
\hline & \multirow[t]{3}{*}{ Years in education } & Up to 10 & 62 & 20.6 & \\
\hline & & $11-15$ & 157 & 52.1 & \\
\hline & & $16+$ & 80 & 26.5 & \\
\hline & \multirow[t]{8}{*}{ Employment status } & Paid or self-employed & 80 & 26.5 & \\
\hline & & Voluntary work & 14 & 4.7 & \\
\hline & & Retired & 173 & 57.5 & \\
\hline & & Housewife/husband & 13 & 4.3 & \\
\hline & & Unemployed & 5 & 1.7 & \\
\hline & & Exempt through disability & 2 & 0.7 & \\
\hline & & Full-time caregiver & 10 & 3.3 & \\
\hline & & Other & 4 & 1.3 & \\
\hline & \multirow{2}{*}{$\begin{array}{l}\text { Taking days off work to } \\
\text { provide care for person }\end{array}$} & Yes & 46 & 15.3 & \\
\hline & & No & 50 & 16.6 & \\
\hline & Having a long-term & Yes & 103 & 34.2 & \\
\hline & health condition & No & 198 & 65.8 & \\
\hline & Living with person & Yes & 210 & 69.8 & \\
\hline & with dementia & No & 91 & 30.2 & \\
\hline & Hours/day leaving the & Never & 21 & 7.0 & \\
\hline & \multirow[t]{4}{*}{ person at home alone } & Up to 4 & 95 & 31.6 & \\
\hline & & $4-8$ & 44 & 14.6 & \\
\hline & & $8-12$ & 11 & 3.7 & \\
\hline & & $12-16$ & 38 & 12.6 & \\
\hline & \multicolumn{2}{|l|}{$\begin{array}{l}\text { Hours/week spent visiting } \\
\text { the person (for non-co-residents) }\end{array}$} & 86 & 94 & $14.5 ; 13.7 ; 1-70$ \\
\hline & \multicolumn{2}{|l|}{ Times/week travelled to visit } & 87 & 96 & $4.9 ; 5.5 ; 0-30$ \\
\hline & \multicolumn{2}{|l|}{ Distance travelled to } & 87 & 96 & $26.5 ; 32.5 ; 0-140$ \\
\hline & \multirow[t]{2}{*}{ Received help from others } & Yes & 144 & 47.8 & \\
\hline & & No & 155 & 51.5 & \\
\hline & \multicolumn{2}{|l|}{$\begin{array}{l}\text { Hours/week receiving } \\
\text { help from others }\end{array}$} & 143 & 47.5 & $10.1 ; 24.7 ; 1-168$ \\
\hline \multirow{10}{*}{$\begin{array}{l}\text { Participants } \\
\text { with dementia }\end{array}$} & \multirow[t]{2}{*}{ Gender } & Male & 172 & 57.1 & \\
\hline & & Female & 129 & 42.9 & \\
\hline & Age & & 300 & 99.7 & $79.6 ; 6.6 ; 65-95$ \\
\hline & \multirow[t]{3}{*}{ Ethnicity } & White & 294 & 97.7 & \\
\hline & & Black & 3 & 1 & \\
\hline & & Asian & 4 & 1.3 & \\
\hline & $\mathrm{MoCA}^{1}$ & & 293 & 97 & $20.0 ; 3.1 ; 13-26$ \\
\hline & DAD score ${ }^{2}$ & & 293 & 97 & $77.6 ; 20.6 ; 5-100$ \\
\hline & HADS - anxiety ${ }^{3}$ & & 293 & 97 & $4.0 ; 2.3 ; 0-13$ \\
\hline & HADS - depression ${ }^{3}$ & & 293 & 97 & $4.5 ; 2.8 ; 0-14$ \\
\hline
\end{tabular}

${ }^{*}$ Data for some participants are missing. ${ }^{1}$ Montreal Cognitive Assessment [41]. ${ }^{2}$ Disability Assessment for Dementia [44]. ${ }^{3}$ Hospital Anxiety and Depression Scale [45].

lamented the fact that while their spouse previously helped in the house, they were now the only ones doing house chores:

I mean he's retired but I haven't retired, I still have to do everything I always did. In years gone by, $G$. was good at cooking and he'd do the washing up.
Well now he just sits there and waits until it appears in front of him. C19, W, 86 years

The caring routine also involved numerous medical appointments, which had time implications, particularly for the caregivers who did not live with the person with dementia. Caregivers' responsibilities 
Table 2

Hierarchical regression analysis predicting caregiver burden

\begin{tabular}{lccc}
\hline & B & SE B & $\beta$ \\
\hline Step 1 & & & \\
Constant & 4.22 & 1.37 & -0.6 \\
Age & -0.02 & 0.02 & 0.13 \\
Sex & 0.92 & 0.43 & \\
Step 2 & & & \\
Constant & 9.80 & 1.51 & $-0.10(p=0.081)$ \\
Age & -0.03 & 0.01 & $0.11(p=0.057)$ \\
Sex & 0.77 & 0.40 & $-0.38(p=0.00)$ \\
DAD & -0.06 & 0.01 & \\
Step 3 & & & $-0.09(p=0.098)$ \\
Constant & 9.14 & 1.52 & $-11(p=0.055)$ \\
Age & -0.02 & 0.01 & $-0.38(p=0.00)$ \\
Sex & 0.77 & 0.40 & $0.13(p=0.022)$ \\
DAD & -0.06 & 0.01 & \\
HADS-Anxiety & \\
\hline
\end{tabular}

$\mathrm{R}^{2}=0.02$ for step $1 ; \Delta \mathrm{R}^{2}=0.14$ for step $2(p=0.00) ; \Delta \mathrm{R}^{2}=0.02$ for step 3 ( $p=0.02)$. ${ }^{1}$ Disability Assessment for Dementia [44].

${ }^{2}$ Hospital Anxiety and Depression Scale [45].

also had a negative impact on respite opportunities:

I can still go out and do, I don't go to everything that comes my way, but I still go to my meetings and I can leave him, but I don't stay out as long as I maybe would in the past. C02, W, 86 years

Several other caregivers reported that although they recognized a need to have "me time", they still prioritized the needs of the person they cared for. One caregiver reported having to give up respite time, because of the costs of having the person she cared for attend a day center:

I need to be doing something to, protect myself. I was probably going to go to Pilates, but I haven't got there. Well, I have to see if there is anything for P. on that night. C15, W, 67 years

I used to drop him off and it was two hours and I could do what I wanted. But it was costing $€ 60$, which is a lot every week, so he stopped going there. C12, W, 65 years

Overall, the qualitative interviews highlighted an association between caregiver's time spent visiting or caring for the person, consequent reduction of respite and strain. They also validated the quantitative findings linking higher caregiver strain to increased functional impairment (DAD: $\mathrm{r}=-0.37, p<0.01, n=291$ ) and cognitive deterioration (MoCA: $\mathrm{r}=-0.17, p<$ $0.01)$ of the person with dementia.

\section{Physical health and caring}

The caregivers discussed at length about how caring for the person with dementia was linked to their own physical health, particularly the caregiverspouses, who were often dealing with their own challenges related to the process of aging. A caregiver reported how, because of age-related frailty, she had experienced difficulties helping her husband after a fall:

There was suddenly this great big thump upstairs. I dashed upstairs and he was trapped between the wardrobe and the chair at the side of it and he couldn't move. I managed to get the chair out of the way but I can't lift him up because I have got rheumatoid arthritis. C09, W, 81 years

At the same time, physical ailments could occur as a result of caring for the person with dementia. For example, some caregivers reported physical fatigue as a result of carrying out caring duties:

It's difficult to get out, because you are so tired at the end of the day that all you feel like doing is sitting down! C13, W, 73 years

Overall, the qualitative interviews supported the quantitative findings linking health conditions to higher strain $(U=7856, p<0.01)$ and lower QoL $(U=3766, p<0.01)$.

\section{Social needs of caregivers}

Caregivers reported that they actively sought support in the community to combat feelings of social isolation and gather useful information on dementia care. The dementia-friendly activities that caregivers attended in the community as a result of their involvement in PrAISED gave them an opportunity to establish an empathetic connection and share their experience with other caregivers on a similar journey:

By me going... I chat to other people that have got similar problems. And so in a way I quite look forward to going because rather than the little circle I've already got, I see a little bit bigger circle. I mean we're all in the same boat. C02, W, 86 years

Many were also the benefits that the caregivers obtained from interacting with the therapists delivering the PrAISED intervention. Some caregivers stated that the therapists offered valuable advice on how to better take care of the person with dementia:

(The support worker) has helped me handling M., you know, giving me advice and this sort of thing. C11, H, 74 years

Counting on the help of others also presented opportunities for the caregiver to have respite from caring duties. One caregiver reported that she could leave her husband at home with neighbors, so she could safely attend to other engagements: 
Table 3

Characteristics of sample of qualitative interviews

\begin{tabular}{|c|c|c|c|c|c|c|c|c|c|}
\hline \multirow[b]{2}{*}{ ID } & \multicolumn{4}{|c|}{ Caregiver } & \multirow[b]{2}{*}{$\begin{array}{c}\text { Relationship to } \\
\text { person with } \\
\text { dementia }\end{array}$} & \multicolumn{4}{|c|}{ Participant with dementia } \\
\hline & Gender & Age & Ethnicity & $\begin{array}{l}\text { Living with } \\
\text { person with } \\
\text { dementia? }\end{array}$ & & Gender & Age & Ethnicity & $\begin{array}{l}\text { MoCA }^{1} \text { score } \\
\text { of participant } \\
\text { with dementia }\end{array}$ \\
\hline $\mathrm{C} 01$ & $\mathrm{~F}$ & 73 & White & No & Sister & M & 70 & White & 18 \\
\hline $\mathrm{C} 02$ & $\mathrm{~F}$ & 86 & White & Yes & Wife & M & 88 & White & 21 \\
\hline $\mathrm{C} 03$ & $\mathrm{~F}$ & 67 & White & Yes & Wife & M & 65 & White & 21 \\
\hline C04 & $\mathrm{F}$ & 47 & Black & No & Daughter & $\mathrm{F}$ & 72 & Black & 18 \\
\hline $\mathrm{C} 05$ & $\mathrm{~F}$ & 58 & White & No & Daughter & $\mathrm{F}$ & 90 & White & 20 \\
\hline C06 & M & 78 & White & Yes & Husband & $\mathrm{F}$ & 75 & White & 18 \\
\hline $\mathrm{C} 07$ & $\mathrm{~F}$ & 72 & White & Yes & Husband & $\mathrm{F}$ & 72 & White & 26 \\
\hline $\mathrm{C} 08$ & $\mathrm{~F}$ & 73 & White & Yes & Wife & M & 78 & White & 15 \\
\hline $\mathrm{C} 09$ & $\mathrm{~F}$ & 81 & White & Yes & Wife & M & 87 & White & 18 \\
\hline $\mathrm{C} 10$ & M & 79 & White & Yes & Husband & $\mathrm{F}$ & 71 & White & 20 \\
\hline C11 & M & 74 & White & Yes & Husband & $\mathrm{F}$ & 74 & White & 23 \\
\hline $\mathrm{C} 12$ & $\mathrm{~F}$ & 65 & White & Yes & Wife & M & 88 & White & 18 \\
\hline $\mathrm{C} 13$ & $\mathrm{~F}$ & 73 & White & Yes & Wife & M & 77 & White & 23 \\
\hline C14 & $\mathrm{F}$ & 75 & White & Yes & Wife & M & 78 & White & 24 \\
\hline $\mathrm{C} 15$ & $\mathrm{~F}$ & 67 & White & Yes & Wife & M & 78 & White & 19 \\
\hline $\mathrm{C} 16$ & $\mathrm{~F}$ & 70 & White & Yes & Wife & M & 69 & White & 20 \\
\hline $\mathrm{C} 17$ & $\mathrm{~F}$ & 79 & White & Yes & Wife & M & 80 & White & 19 \\
\hline $\mathrm{C} 18$ & M & 81 & White & Yes & Husband & $\mathrm{F}$ & 77 & White & 22 \\
\hline C19 & M & 86 & White & Yes & Wife & M & 91 & White & 15 \\
\hline $\mathrm{C} 20$ & $\mathrm{~F}$ & 89 & White & Yes & Wife & $\mathrm{M}$ & 92 & White & Not available \\
\hline
\end{tabular}

${ }^{1}$ Montreal Cognitive Assessment [41]. 
Table 4

Themes identified through thematic analysis and operational definitions

\begin{tabular}{|c|c|c|c|c|c|c|}
\hline \multicolumn{2}{|c|}{ Emerging themes } & & \multicolumn{2}{|c|}{ Solidifying themes* } & & \multirow{2}{*}{$\begin{array}{l}\text { Final themes** and } \\
\text { operational definitions } \\
\text { Developed by CDL and fed back } \\
\text { to JL, MG and VvdW for consensus }\end{array}$} \\
\hline $\begin{array}{l}\text { Identified by academic } \\
\text { researcher (JL) }\end{array}$ & $\begin{array}{l}\text { Identified by PPI } \\
\text { contributor (MG) }\end{array}$ & & $\begin{array}{l}\text { Identified by first } \\
\text { academic analyst } \\
\text { (CDL) }\end{array}$ & $\begin{array}{l}\text { Identified by second } \\
\text { academic analyst } \\
\text { (VvdW) }\end{array}$ & & \\
\hline $\begin{array}{l}\text { 1. Support (or lack thereof) } \\
\text { (i.e., from family, community, } \\
\text { friends, paid caregivers, } \\
\text { the PrAISED team) }\end{array}$ & $\begin{array}{l}\text { 6. Support from others (i.e., } \\
\text { Support and advice given } \\
\text { to person with dementia and } \\
\text { caregiver by other family } \\
\text { and friends) }\end{array}$ & & Support (1 and 6) & $\begin{array}{l}\text { Support network } \\
(1 \text { and } 6)\end{array}$ & & $\begin{array}{l}\text { Social needs of caregivers: Positive or } \\
\text { negative social aspects of caring, such } \\
\text { as expanding social contacts, social } \\
\text { isolation and support from others }\end{array}$ \\
\hline $\begin{array}{l}\text { 2. Challenges (i.e., lack of } \\
\text { respite, increased dependency } \\
\text { of person with dementia, } \\
\text { adjustments, isolation, } \\
\text { decrease in previous } \\
\text { skills) }\end{array}$ & $\begin{array}{l}\text { 7. Additional demands (i.e., } \\
\text { additional demands made } \\
\text { on caregivers own time } \\
\text { and space) }\end{array}$ & & $\begin{array}{l}\text { Challenges } \\
(2,7, \text { and } 8)\end{array}$ & $\begin{array}{l}\text { New limitations } \\
(2,3,7 \text {, and } 8)\end{array}$ & & $\begin{array}{l}\text { Practical aspects of caring: Positive or } \\
\text { negative practical aspects of caring, such } \\
\text { as improving caring skills, demands } \\
\text { on time and space, and change of life plans }\end{array}$ \\
\hline $\begin{array}{l}\text { 3. Independence (i.e., travel } \\
\text { and transport, change } \\
\text { of holidays plans) }\end{array}$ & $\begin{array}{l}\text { 8. Restrictions (i.e., } \\
\text { restrictions of life and } \\
\text { interests placed on } \\
\text { the caregiver) }\end{array}$ & Synthesis & $\begin{array}{l}\text { Independence } \\
\text { (3) }\end{array}$ & & Synthesis & \\
\hline $\begin{array}{l}\text { 4. Benefits (i.e., expanding } \\
\text { activities, groups, physical or } \\
\text { social interactions, increased } \\
\text { motivation to be physically } \\
\text { active, physical and } \\
\text { practical improvements) }\end{array}$ & $\begin{array}{l}\text { 9. Physical health (impact of } \\
\text { ageing and care burden } \\
\text { on physical health) }\end{array}$ & & Benefits (4) & $\begin{array}{l}\text { Activities of } \\
\text { daily living (4) }\end{array}$ & & $\begin{array}{l}\text { Emotional impact of the caring role: Positive } \\
\text { or negative feelings, including adjusting and } \\
\text { accepting change, worry, stress, depression, } \\
\text { anger, tension, desperation, fear, guilt, } \\
\text { and sense of purpose }\end{array}$ \\
\hline \multirow[t]{2}{*}{$\begin{array}{l}\text { 5. Emotions (i.e., loyalty, duty, } \\
\text { acceptance of change, anxiety, } \\
\text { worry, depression, guilt, } \\
\text { anger and frustration) }\end{array}$} & $\begin{array}{l}\text { 10. Mental impact (i.e., worry, } \\
\text { stress, depression, anger, } \\
\text { tension, loneliness, } \\
\text { desperation, fear, guilt, feeling } \\
\text { overwhelmed, loss of purpose) }\end{array}$ & & $\begin{array}{l}\text { Emotions } \\
(5 \text { and } 10)\end{array}$ & $\begin{array}{l}\text { Psychological } \\
\text { factors (5 and 10) }\end{array}$ & & \\
\hline & & & $\begin{array}{l}\text { Physical health } \\
\text { (9) }\end{array}$ & $\begin{array}{l}\text { Physical health } \\
\text { (9) }\end{array}$ & & $\begin{array}{l}\text { Physical health and caring: Positive or } \\
\text { negative impact of caring on physical health, } \\
\text { such as physical illness, exhaustion, } \\
\text { tiredness and fatigue }\end{array}$ \\
\hline
\end{tabular}


We've got all the neighbours and friends and they've all rallied round. And you know, they come in and they say, you go off for a couple of hours and I go off and they sit with her. C11, $\mathrm{H}, 74$ years

While extra support was frequently available for sibling and child-caregivers, in line with the quantitative findings, several spouse-caregivers reported that they did not receive any extra support from others. This could depend on a number of factors. For example, they might have children who lived far away. Another frequently reported factor was that caregivers preferred not to burden other family members and try, as much as possible, to make it on their own:

We're trying to be independent and all that, we don't want to bother our children. We'd rather soldier on. $\mathrm{ClO}, \mathrm{H}, 79$ years

Another factor causing a lack of support was limited social opportunities. Several spouse-caregivers reported that, as a result of dementia progression, they had lost all social contacts. Because of the lack of social opportunities, these caregivers manifested a need to actively seek social opportunities outside the home, in order to safeguard their wellbeing:

Since $G$. has given up exercise, he's become less sociable. As a result, I've become less sociable. Ioften don't see other people. There's two things I go out to during the week and I really find now that I need those things to go to just to be with other people. C03, W, 67 years

Overall, the interviews confirmed the quantitative findings linking lower QoL and perceived health to being married to $(U=4798, p<0.01)$ and living with the person with dementia $(U=5578, p<0.01)$, with spouses-caregivers reporting greater reduction in social opportunities and increased risk of social isolation as a result of dementia progression and caring duties.

\section{Emotional impact of the caring role}

Caregivers expressed a great sense of commitment to the wellbeing of the person they cared for. Most were happy to offer support and help at any time of the day and night:

I love M. dearly and I will do whatever I can to support him and to keep his independence as long as possible. He can pick up the phone any time day or night. C01, S, 73 years

Because of their investment in the person's wellbeing, some caregivers manifested worries and anxiety about safety, particularly when having to leave the person unattended. Safety concerns were often also accompanied by a sense of guilt, when the caregiver had to leave the person with dementia at home alone:

I' $m$ on the phone every half hour or so while I' $m$ away, just to check that she's all right. C06, H, 68 years

I feel guilty about going out and leaving him to do the shopping. C09, W, 81 years

Caring was often driven by a sense of duty and responsibility, particularly among spouses. At times, caregivers' words implied a sense of being trapped in the role of caregiver. In fact, mixed feelings were quite common:

As a caregiver I'm just, well, I've got to be here anyway, because I' $m$ married to the lady. CO6, $\mathrm{H}, 68$ years

Although not necessarily openly manifested, it seemed that frustration often derived from the difficulty of accepting the inevitable changes that dementia caused. The changes and adjustment that the progression of dementia required also caused feelings of helplessness and hopelessness:

The only worry I've got is the loss of short-term memory, but there's nothing I can do about it. It's sometimes very frustrating; you have to repeat yourself three or four time. C06, $\mathrm{H}, 68$ years

I get down about it sometimes. I get a bit depressed. It's not very often I' $m$ like that, but if I get it, I' $m$ really down! C08, W, 73 years

Others were more accepting of change and this seemed to safeguard their own emotional wellbeing. These cares appreciated the possibility that change was not necessarily negative and that the person could, for example, take up new activities and learn new skills:

He goes to this chair yoga on a Tuesday morning round at the community centre. For me to see him doing something that he couldn't do before is a bonus. C02, $W, 86$ years

Overall, the qualitative interviews found that the caregivers exhibited co-existing positive and negative feelings associated with caring, with stresses and rewards that were often not easy to reconcile.

\section{DISCUSSION}

This mixed-methods study based on data from the PrAISED RCT investigated caregivers' strain, QoL and perceived health, and reported on the experience of caring for someone with dementia.

The study revealed how caring is characterized by a complex interaction of contradictory emotions. Our findings appear in contrast to the clear-cut 
division operated in the previous literature between the negative emotions exhibited by those who become caregivers not by personal choice and the positive ones experienced by those who do [50]. In the interviews, participants disclosed a range of negative feelings and emotions including frustration, anger, and depression. These qualitative findings were compounded by the significant association we found between caregivers' burden and QoL, especially in the presence of high levels of anxiety and disability of the person with dementia. Although to a lesser extent, participants also reported positive emotions linked to their caring role, including a sense of fulfilling one's responsibilities, pleasure and pride in seeing the person can still do some activities or take up new ones, and reassurance in the availability of support from the family and the community.

Another important finding was that the experience of caring varied quite markedly because of the diverse range of caregivers' characteristics. Older spousecaregivers faced disadvantaged circumstances that greatly affected their overall experience of caring. While some research found higher life satisfaction in older caregivers compared with younger ones [51-54], this study found that caregiver's age was significantly associated with strain, supporting evidence on the greater challenges of aging while undertaking a caregiver's role [55].

As in previous studies [56, 57], residing with the person with dementia was also associated with higher caregiver burden in the quantitative findings, and reduced contact with others in the qualitative ones. In line with previous research $[25,26]$, we found that older spouse caregivers in particular had a limited support network and experienced an overall sense of isolation and loneliness, both without and within the relationship with the person with dementia [55]. On the other hand, the younger caregivers might be more likely to have work and (other) family commitments outside the caregiving role, which could provide them with increased social opportunities and respite.

Despite the recognition of the benefits of social contacts [58], this lack of a support network was at times compounded and reinforced by the caregivers' reluctance to seek help from others. A potential explanation can be traced back to cultural factors, making older generations feeling less entitled to ask for help and caring duties seen as a responsibility within long-term relationship and marital vows [55]. Deeply rooted cultural imperatives to functional independence as a prerequisite for adult status and competence might also be at play.
While caregiver strain has been long-established as a potential factor in the development of ill-health $[3,15-23,58]$, this study found that health conditions may not only develop as a result of strain, but actually be the cause of it. The quantitative element of this study showed that having a health condition was associated with decreased QoL and increased caregiver strain. The qualitative data provided some further insight into this interaction, showing that presenting with health conditions (i.e., more frequent age-related ailments such as arthritis), generated strain because of the reduced opportunities to access community support (e.g., because of reduced mobility) or because the caregiver could not provide adequate care to the person (e.g., because of physical limitations) [59].

Overall, findings from the experience of older caregivers rebutted the "adaptation hypothesis" [28, 29], suggesting that caregivers successfully adapt to coping with burden over time. Instead, because of the unique combination of circumstances in which the older caregivers found themselves, their experience seems to validate the "wear and tear" theory [30, 31], suggesting the accumulation of burden over time.

This work was characterized by certain strengths and limitations. It is among the few studies exploring caregivers' experience of caring for someone with dementia through a mixed-methods design based on large samples. However, certain demographic characteristics (e.g., ethnicity) were under-represented, requiring future research to include harder-to-reach groups, in order to gather more culturally-diverse evidence.

Some biased results may have been caused by the self-reporting measures in the quantitative assessments, as well as during the qualitative interviews with participants. It was observed that some caregivers were reserved in discussing sensitive subjects in the presence of the person with dementia, a challenge which has been previously reported [55, 60]. Therefore, efforts should be made to ensure that caregivers feel comfortable to open up during the research process, by for example, provision of alternative arrangements (e.g., two researchers attending the interview session, so that one can supervise the person with dementia during data collection). Another study limitation was the lack of longitudinal data to look at stability/trajectory of caregiver responses.

This study has identified certain support (emotional and practical) needs that present important implications for practice. There is a need to provide support services that better respond to the complexity 
of caregivers' life situations. Because of the blurred boundary between being a care-provider and a care-receiver, caregivers may find enormous difficulties in finding support for themselves [61]. In addition, given the emphasis on person-with-dementia-centered approaches to care delivery, professionals may struggle to include caregivers as the recipients of care [62]. In line with Oliveira, Sousa, and Aubeeluck [63], we advocate that dedicated strategies for caregivers should be in place to address their unique challenges [61].

Building on the positive outcomes associated with caring, activities that are enjoyed by both people with dementia and their spouses may represent an inclusive strategy to promote positive relationship between the caregiver and the person, and in turn reduce caregiver burden [64]. Initiatives of this sort might be particularly appropriate for older spouse caregivers, who share similar demographics (and potential interests) with the person they care for. A recent impact evaluation of a dementia-friendly exercise class [65], as well as established evidence around dementia cafés [66] and Singing for the Brain [67] identified numerous benefits for caregivers, including networking opportunities to share and learn from peers.

Caregiver peer-support groups could also represent a helpful resource. These groups are usually based on a psychoeducational model, which encourages group members to gather information and share support with peers [61]. Integrating IT peer-support platforms might be able to address isolation/barriers of access to community support experienced by caregivers who live in remote geographical locations [61]. Telemedicine is becoming increasingly used in assisting caregivers by offering support (e.g., opportunity to be in contact with other caregivers and clinicians) and services (e.g., health and social care or third sector organizations providing educational material about dementia).

In conclusion, this study found that while caring for someone with dementia can present with both positive and negative experiences, older spouse caregivers living with the person with dementia present with a high risk of ill-health, social isolation, and lower QoL. We advocate for the provision of dedicated intervention programs and support strategies in the community, which are age-friendly and adequately respond to the needs of older caregivers at different stages of their caregiving journey. While there is recognition that it is essential to support caregivers because they are key to supporting people with dementia and because they struggle in a number of ways, the current policy rhetoric should be matched by (successful) commensurate efforts.

\section{ACKNOWLEDGMENTS}

This study presents independent research funded by the United Kingdom National Institute for Health Research (NIHR) under its Programme Grants for Applied Research funding scheme (RP-PG-061420007). The views expressed are those of the authors and not necessarily those of the NIHR or the Department of Health and Social Care.

Authors' disclosures available online (https:// www.j-alz.com/manuscript-disclosures/20-1257r3).

\section{SUPPLEMENTARY MATERIAL}

The supplementary material is available in the electronic version of this article: https://dx.doi.org/ 10.3233/JAD-201257.

\section{REFERENCES}

[1] Alzheimer's Society (2020) How many people have dementia and what is the cost of dementia care? https:// www.alzheimers.org.uk/about-us/policy-and-influencing/ dementia-scale-impact-numbers, Accessed on March 24, 2020.

[2] Dementia caregivers count (2020) Facts and figures. https:// dementiacaregivers.org.uk/for-dementia-professionals/ key-facts-figures/, Accessed on March 24, 2020.

[3] Alzheimer's Association (2007) Alzheimer's Disease Facts and Figures. Alzheimer's Association, Chicago, IL.

[4] Stirling C, Andrews S, Croft T, Vickers J, Turner P, Robinson A (2010) Measuring dementia caregivers' unmet need for services-an exploratory mixed method study. BMC Health Serv Res 10, 122.

[5] La Fontaine J, Read K, Brooker D, Evans S, Jutlla K (2016) The experiences, needs and outcomes for caregivers of people with dementia: Literature review. Association for Dementia Studies, University of Worcester, Worcester, UK.

[6] Campbell P, Wright J, Oyebode J, Job D, Crome P, Bentham P, Jones L, Lendon C (2008) Determinants of burden in those who care for someone with dementia. Int $J$ Geriatr Psychiatry 23, 1078-1085.

[7] Cooper C, Katona C, Orrell M, Livingston G (2006) Coping strategies and anxiety in caregivers of people with Alzheimer's disease: The LASER-AD study. J Affect Disord 90, $15-20$.

[8] Gaugler JE, Roth DL, Haley WE, Mittleman MS (2008) Can counseling and support reduce burden and depressive symptoms in caregivers of people with Alzheimer's disease during the transition to institutionalization? Results from the New York University caregiver intervention study. $J \mathrm{Am}$ Geriatr Soc 56, 421-428.

[9] Clare L, Wilson BA, Carter G, Breen K, Berrios GE, Hodges JR (2002) Depression and anxiety in memory clinic attenders and their caregivers: Implications for evaluating the 
effectiveness of cognitive rehabilitation interventions. Int $J$ Geriatr Psychiatry 17, 962-967.

[10] Adkins VK (1999) Treatment of depressive disorders of spousal caregivers of persons with Alzheimer's disease: A review. Am J Alzheimers Dis 14, 289-293.

[11] Cooper C, Balamurali TBS, Livingston G (2007) A systematic review of the prevalence and covariates of anxiety in caregivers of people with dementia. Int Psychogeriatr 19, 175-195.

[12] Livingston G, Mahoney R, Regan C, Katona C (2005) The caregivers for Alzheimer's disease Problems Scale (CAPS): Development of a new scale within the LASER-AD study. Age Ageing 34, 287-290.

[13] Schulz R, O’Brien AT, Bookwala J, Fleissner K (1995) Psychiatric and physical morbidity effects of dementia caregiving: Prevalence, correlates, and causes. Gerontologist $\mathbf{3 5}$, 771-791.

[14] The 10/66 Dementia Research Group (2004) Care arrangements for people with dementia in developing countries. Int J Geriatr Psychiatry 19, 170-177.

[15] Schulz R, Martire LM (2004) Family caregiving of persons with dementia: Prevalence, health effects, and support strategies. Am J Geriatr Psychiatry 12, 240-249.

[16] Baumgarten M, Battista RN, Infante-Rivard C, Hanley JA, Becker R, Gauthier S (1992) The psychological and physical health of family members caring for an elderly person with dementia. J Clin Epidemiol 45, 61-70.

[17] Haley WE, Levine EG, Brown SL, Bartolucci AA (1987) Stress, appraisal, coping, and social support as predictors of adaptational outcome among dementia caregivers. Psychol Aging 2, 323.

[18] Pruchno RA, Potashnik SL (1989) Caregiving spouses: Physical and mental health in perspective. J Am Geriatr Soc 37, 697-705.

[19] Schulz R, Williamson GM (1997) The measurement of caregiver outcomes in Alzheimer disease research. Alzheimer Dis Assoc Disord 11, 117-124.

[20] Segerstrom SC, Schipper LJ, Greenberg RN (2008) Caregiving, repetitive thought, and immune response to vaccination in older adults. Brain Behav Immun 22, 744-752.

[21] Vedhara K, Bennett PD, Clark S, Lightman SL, Shaw S, Perks P, Hunt MA, Philip JM, Tallon D, Murphy PJ, Jones RW (2003) Enhancement of antibody responses to influenza vaccination in the elderly following a cognitive-behavioural stress management intervention. Psychother Psychosom 72, 245-252.

[22] Vedhara K, Cox NK, Wilcock GK, Perks P, Hunt M, Anderson S, Lightman SL, Shanks NM (1999) Chronic stress in elderly caregivers of dementia patients and antibody response to influenza vaccination. Lancet 353, 627-631.

[23] Vitaliano PP, Zhang J, Scanlan JM (2003) Is caregiving hazardous to one's physical health? A meta-analysis. Psychol Bull 129, 946-972.

[24] Wolinsky FD, Callahan CM, Fitzgerald JF, Johnson RJ (1992) The risk of nursing home placement and subsequent death among older adults. J Gerontol 47, S173-182.

[25] Brodaty H, Hadzi-Pavlovic D (1990) Psychosocial effects on caregivers of living with persons with dementia. Aust $N$ Z J Psychiatry 24, 351-361.

[26] Graham C, Ballard C, Sham P (1997) Caregivers' knowledge of dementia, their coping strategies and morbidity. Int J Geriatr Psychiatry 12, 931-936.

[27] Gaugler JE, Kane RL, Kane RA, Newcomer R (2005) Unmet care needs and key outcomes in dementia. $J \mathrm{Am}$ Geriatr Soc 53, 2098-2105.
[28] Johnson CL, Catalane DJ (1983) A longitudinal study of family supports to impaired elderly. Gerontologist 23, 612618.

[29] Rabins PV, Fitting MD, Eastham J, Zabora J (1990) Emotional adaptation over time in care-givers for chronically ill elderly people. Age Ageing 19, 185.

[30] Townsend A, Noelker L, Deimling G, Bass D (1989) Longitudinal impact of interhousehold caregiving on adult children's mental health. Psychol Aging 4, 393.

[31] Zarit SH, Todd PA, Zarit JM (1986) Subjective burden of husbands and wives as caregivers: A longtitudinal study. Gerontologist 26, 260-266.

[32] Cohen C, Pushkar Gold D, Shulman KI, Zucchero CA (1994) Positive aspects in caregiving: An overlooked variable in research. Can J Aging 13, 378-391.

[33] Andrén S, Elmståhl S (2005) Family caregivers' subjective experiences of satisfaction in dementia care: Aspects of burden, subjective health and sense of coherence. Scand $J$ Caring Sci 19, 157-168.

[34] Cohen CA, Colantonio A, Vernich L (2002) Positive aspects of caregiving: Rounding out the caregiving experience. Int J Geriatr Psychiatry 12, 184-188.

[35] Walker AJ, Jones LL, Martin SK (1989) Relationship quality and the benefits and costs of caregiving. Paper presented at: Meeting of the National Council on Family Relations; New Orleans.

[36] Sanders S (2005) Is the glass half empty or half full? Reflections on strain and gain in caregivers of individuals with Alzheimer's disease. Soc Work Health Care 40, 57-73.

[37] Lundh U (1999) Family caregivers: Sources of satisfaction among Swedish caregivers. Br J Nurs 8, 647-652.

[38] Grant G, Nolan M (1993) Informal caregivers: Sources and concomitants of satisfaction. Health Soc Care 1, 147-159.

[39] Chiao CY, Wu HS, Hsiao CY (2015) Caregiver burden for informal caregivers of patients with dementia: A systematic review. Int Nurs Rev 62, 340-350.

[40] Bajwa RK, Goldberg SE, Van der Wardt V, Burgon C, Di Lorito C, Godfrey M, Dunlop M, Logan P, Masud T, Gladman J, Smith H (2019) A randomised controlled trial of an exercise intervention promoting activity, independence and stability in older adults with mild cognitive impairment and early dementia (PrAISED)- A Protocol. Trials 20, 815.

[41] Nasreddine ZS, Phillips NA, Bédirian V, Charbonneau $\mathrm{S}$, Whitehead V, Collin I, Cummings JL, Chertkow H (2005) The Montreal Cognitive Assessment, MoCA: A brief screening tool for mild cognitive impairment. J Am Geriatr Soc 53, 695-699.

[42] Robinson BC (1983) Validation of a Caregiver Strain Index. J Gerontol 38, 344-348.

[43] EuroQol (1990) EuroQol-a new facility for the measurement of health-related quality of life. Health Policy 16, 199-208.

[44] Gélinas I, Gauthier L, McIntyre M, Gauthier S (1999) Development of a functional measure for persons with Alzheimer's disease: The disability assessment for dementia. Am J Occup Ther 53, 471-481.

[45] Zigmond AS, Snaith RP (1983) The Hospital Anxiety and Depression Scale. Acta Psychiatr Scand 67, 361-370.

[46] IBM Corp. (2017) IBM SPSS ${ }^{\circledR}$ Statistics for Windows, Version 25.0. IBM Corp, Armonk, NY.

[47] QSR International Pty Ltd. (2018) NVivo ${ }^{\circledR}$ Qualitative Data Analysis Software. QSR International Pty Ltd: Melbourne, Australia.

[48] Braun V, Clarke V (2006) Using thematic analysis in psychology. Qual Res Psychol 3, 77-101. 
[49] Janssen B, Szende A (2014) Population Norms for the EQ5D. In Self-Reported Population Health: An International Perspective based on EQ-5D, Szende A, Janssen B, Cabases J, eds. Springer, Dordrecht, pp. 19-30.

[50] Pyke KD, Bengston VL (1996) Caring more or less: Individualistic and collectivist systems of family eldercare. $J$ Marriage Fam 58, 379-392.

[51] Anderson LA, Edwards VJ, Pearson WS, Talley RC, McGuire LC, Andresen EM (2013) Adult caregivers in the United States: Characteristics and differences in well-being, by caregiver age and caregiving status. Prev Chronic Dis 10, E135.

[52] Ekwall AK, Hallberg IR (2007) The association between caregiving satisfaction, difficulties and coping among older family caregivers. $J$ Clin Nurs 16, 832-844.

[53] Harwood DG, Barker WW, Ownby RL, Bravo M, Aguero H, Duara R (2000) Predictors of positive and negative appraisal among Cuban American caregivers of Alzheimer's disease patients. Int J Geriatr Psychiatry 15, 481-487.

[54] Tang M (2011) Can cultural values help explain the positive aspects of caregiving among Chinese American caregivers. J Gerontol Soc Work 54, 551-569.

[55] Greenwood N, Pound C, Brearley S, Smith R (2019) A qualitative study of older informal caregivers' experiences and perceptions of their caring role. Maturitas 124, 1-7.

[56] Kim H, Chang M, Rose K, Kim S (2012) Predictors of caregiver burden in caregivers of individuals with dementia. $J$ Adv Nurs 68, 846-855.

[57] Brodaty H, Donkin M (2009) Family caregivers of people with dementia. Dialogues Clin Neurosci 11, 217.

[58] Oliveira D, Vass C, Aubeeluck A (2017) Quality of life on the views of older family caregivers of people with dementia. Dementia 18, 990-1009.

[59] Schulz R, Sherwood PR (2008) Physical and mental health effects of family caregiving. J Soc Work Educ 44, 105-113.
[60] Prick AE, de Lange J, van 't Leven N, Pot AM (2014) Process evaluation of a multicomponent dyadic intervention study with exercise and support for people with dementia and their family caregivers. Trials $\mathbf{1 5}, 401$.

[61] Glasby J, Thomes S (2018) Understanding and responding to the needs of the caregivers of people with dementia in the UK, US and beyond. University of Birmingham, UK.

[62] Pollock K, Wilkinson S, Perry-Young L, Turner N, Schneider J (2020) What do family care-givers want from domiciliary care for relatives living with dementia? A qualitative study. Ageing Soc, doi: 10.1017/S0144686X20000185

[63] Oliveira D, Sousa L, Aubeeluck A (2018) What would most help improve the quality of life of older family caregivers of people with dementia? A qualitative study of caregivers' views. Dementia 19, 939-950.

[64] Searson R, Hendry AM, Ramachandran R, Burns A, Purandare N (2008) Activities enjoyed by patients with dementia together with their spouses and psychological morbidity in caregivers. Aging Ment Health 12, 276-282.

[65] Long, A, Di Lorito, C, Logan, P, Booth, V, Howe, L, HoodMoore, V, van der Wardt V (2020) The impact of a dementiafriendly exercise class on people living with dementia: A mixed methods study. Int J Environ Res Public Health 17, 4562.

[66] Greenwood N, Smith R, Akhtar F, Richardson A (2017) A qualitative interview study of caregivers' experiences of dementia cafés: A place to feel supported and be yourself. BMC Geriatr 17, 164.

[67] Osman SE, Tischler V, Schneider J (2016) 'Singing for the Brain': A qualitative study exploring the health and wellbeing benefits of singing for people with dementia and their caregivers. Dementia 15, 1326-1339 